Original article

\title{
Gender influences physical activity changes during adolescence: The HELENA study
}

\author{
L. Béghin ${ }^{\text {a, }}{ }^{*}$, J. Vanhelst ${ }^{\text {a }}$, E. Drumez ${ }^{\text {b }}$, J.H. Migueles ${ }^{\text {c }}$, O. Androutsos ${ }^{\text {d }}$, K. Widhalm ${ }^{\text {e }}$, \\ C. Julian ${ }^{\text {f }}$, L.A. Moreno ${ }^{\text {f }}$, S. De Henauw ${ }^{\mathrm{g}}$, \\ F. Gottrand ${ }^{a}$, on behalf of the HELENA study group ${ }^{1}$ \\ ${ }^{a}$ Univ. Lille, CHU Lille, LIRIC UMR 995 Inserm, Clinical Investigation Center, CIC-1403-Inserm-CHU, F-59000 Lille, France \\ ${ }^{\mathrm{b}}$ Univ. Lille, CHU Lille, Department of Biostatistics, EA 2694 - Santé publique: épidémiologie et qualité des soins, F-59000 Lille, France \\ ' PROFITH "PROmoting FITness and Health through physical Activity" Research Group, Department of Physical Education and Sports, Faculty of Sport \\ Sciences, University of Granada, Ctra. Alfacar s/n, 18011 Granada, Spain \\ ${ }^{\mathrm{d}}$ Department of Nutrition and Dietetics, School of Health Science \& Education, Harokopio University, Athens, Greece \\ e Department of Pediatrics, School of Medicine, Vienna University, Vienna, Austria \\ ${ }^{\mathrm{f}}$ GENUD (Growth, Exercise, Nutrition and Development) Research Group, Facultad de Ciencias de la Salud, Zaragoza University, Zaragoza, Spain \\ ${ }^{g}$ Department of Public Health, Faculty of Medicine and Health Sciences, Ghent University, Ghent, Belgium
}

\section{A R T I C L E I N F O}

\section{Article history:}

Received 12 March 2018

Accepted 21 December 2018

\section{Keywords:}

Physical activity

Adolescence

Pubertal status

Europe

Sedentary behavior

\section{S U M M A R Y}

Background: We compared differences in physical activity (PA) between pre/mid-pubertal and postpubertal participants according to gender.

Methods: The study included a total of 1842 healthy participants aged $12.5-17.4$ years, who participated in the Healthy Lifestyle in Europe by Nutrition in Adolescence (HELENA) study. Participants wore a uniaxial accelerometer (ActiGraph ${ }^{\odot}$ GT1M, Pensacola, FL, USA) attached to their lower back for seven consecutive days to measure PA. Pubertal status was assessed by physical examination and the population was classified as pre/mid-pubertal (Tanner stages 1-3) or post-pubertal (Tanner stages 4-5). PA was compared between these groups according to gender during the whole week, on school-free days and on school days, before and after school, and during lessons and recesses.

Results: When comparing the pre/mid-pubertal group with the post-pubertal group, girls' total PA did not differ between groups. However, a slight difference was observed in boys, among whom PA on school-free days showed a difference of $17.6 \%$ between the pre/mid-pubertal group and the post-pubertal group (679 kcounts vs 564 kcounts, respectively; $\mathrm{P}=0.0007$ ) and 20\% (162 kcount vs 135 kcounts; $P=0.006)$ for school recess. There was no difference among girls.

Conclusions: A reduced level of PA in the post-pubertal groups was only observed in boys during nonorganized times such as on school-free days and during school recesses, with a moderate impact on total PA.

(C) 2019 Elsevier Ltd and European Society for Clinical Nutrition and Metabolism. All rights reserved.

\section{Introduction}

Physical activity (PA) is as an important determinant of health and has been shown to have beneficial effects on body composition, metabolic markers, physical fitness and mental health [1,2].

\footnotetext{
* Corresponding author. Antenne pédiatrique du CIC, CIC-P-1403-Inserm-CH\&U de Lille, Hôpital Jeanne de Flandre, CHU de Lille, Avenue Eugène Avinée, F - 59000 Lille Cedex, France.

E-mail address: laurent.beghin@chru-lille.fr (L. Béghin).

1 Collaborators are listed in the Supplementary document.
}

Moreover, decreasing PA during adolescence increases the risk of obesity in later years [3]. Despite these observations, population-level PA is usually below public health recommendations during adolescence [4]. A decrease in PA is generally observed during the transition from childhood to adolescence [5], and has been acknowledged as a causal factor behind the current obesity epidemic [6].

The main factors known to influence PA in adolescents are: (i) individual intrinsic motivation [2,7]; (ii) family factors such as socioeconomic level or parental encouragement [8,9]; and (iii) general factors such as an urban environment (access to green public parks, traffic density), natural conditions (seasons, temperature) and 
societal environments such as daily school schedule [10-12]. However, the causes of a decline in PA during the transition to adolescence [7,12], which then tracks from adolescence to adulthood [13], are not well understood [8]. The analysis of PA changes during the daily cycle and differences between girls and boys could advance our understanding of the PA decline during the transition to adolescence.

The study aim was to compare differences in PA between pre/ mid-pubertal and post-pubertal participants according to gender during the daily cycle of school days and school-free days.

\section{Subjects and methods}

\subsection{Study design and ethical approvals}

Data were collected from the Healthy Lifestyle in Europe by Nutrition in Adolescence (HELENA study; www.helenastudy.com) conducted in European adolescents. The aim of the HELENA study was to obtain a broad range of standardized, reliable, and comparable nutrition- and health-related data from a random sample of European adolescents aged $12.5-17.5$ years. A detailed description of the HELENA study methodology and sampling has been published elsewhere [13,14]. In total, 3528 participants (1844 girls and 1684 boys) meeting the inclusion criteria completed all examinations. The analyses in the present study are based on 1842 healthy participants aged 12.5-17.4 years from seven European cities: Lille (France), Spain Zaragoza (Spain), Dortmund (Germany), Pècs (Hungary), Ghent (Belgium), Roma (Italy) and Athens (Greece). Data were excluded because of missing accelerometer data ( $\mathrm{n}=709)$, missing school schedules $(n=1504)$ and missing Tanner staging information $(\mathrm{n}=401)$.

The study objectives and methodology were explained carefully to each participant and their both parents. Written informed consent was obtained from all participants. The local ethics committee for each country approved the HELENA study, and all procedures were performed in accordance with the ethical standards of the 1975 Helsinki Declaration (as revised in 2008) and the European Good Clinical Practice Guidelines [15].

\subsection{Participant characteristics and physical examinations}

Weight was measured in light clothes, without shoes, to the nearest $0.1 \mathrm{~kg}$ using an electronic scale (SECA 871; SECA, Hamburg, Germany). Height was measured without shoes to the nearest $0.1 \mathrm{~cm}$ using a telescopic height-measuring instrument (SECA 225; SECA). Body mass index (BMI) was calculated using the standard formula $\left(\mathrm{kg} / \mathrm{m}^{2}\right)$. Nutritional status was defined using the sex specific cutoff points established by the World Obesity Federation (formerly the International Obesity Task Force) [16].

Pubertal status was assessed according to Tanner stage, the standard reference method, during a physical examination by a well-trained physician [17]. Signs of puberty were scored according to pubic hair status using the standard pictures of pubic hair development from the Tanner scale. The degree of pubertal development was also assessed according to the size of the testes, scrotum and penis in boys, and according to breast development in girls using the standard pictures of Tanner and five categories for both genders. Following Crowley et al. [18], adolescents' pubertal status was classified into two groups: pre/mid-pubertal (Tanner stages $1-3$ ) and post-pubertal (Tanner stages $4-5$ ). We used this classification because pubertal status correlates with changes in adolescent hormone levels. Previous studies observed changes in adolescent personalities using pubertal status as a marker of the transition and concluded that age was not a good marker [19]. In this context, pubertal status is the most appropriate marker to assess adolescent behavioral changes that may influence PA levels.

\subsection{Physical activity assessment}

The GT1M Monitor (ActiGraph ${ }^{\odot}$, Pensacola, FL, USA) was used to assess PA in free-living conditions. The process for the use of this device, data collection and data cleaning has been described previously [20]. Briefly, a fieldworker researcher at each center completed workshop training in how to instruct participants in using the device. The adolescents were instructed to wear the accelerometer on their lower back on elastic belt and adjustable buckle during seven consecutive days during their normal daily routine. They were also instructed to remove the accelerometer during swimming, showering, bathing and at night.

Data were collected at $15 \mathrm{~s}$ an epoch intervals. After downloading of data, PA levels were converted and expressed as an average PA in mean counts per minute. Data from 06.00 to 23.00 were analyzed. Strings of 20 consecutive minutes recording zero counts were classified as non-wear and excluded from the analysis [21]. Participants who did not record at least 3 days with a minimum of $8 \mathrm{~h}$ of wearing time per day were excluded from the analyses.

PA was expressed as a cumulative amounts counts or the group mean (i.e., boys and girls) kcounts over the one-week wearing period. Next, different periods of time schedule (i.e., school free days, before school, after school, etc) were compared. Moderate vigorous physical activity (MVPA) was defined as minutes when PA was $>2000$ counts/min [20].

\subsection{Adolescent schedule rhythms}

A researcher from each center was instructed to complete a weekly schedule questionnaire to separate school days from school-free days, and to split the school days into different periods, including: (i) school days and school-free days; (ii) hours before and after school; (iii) hours of teaching/lessons; and (iv) before school recesses and lunch breaks. According to each participant's rhythm, the school schedule was separated into three periods: before and after school, during lessons, and during recesses. A detailed time schedule for each participating school class was previously described by Vanhelst et al. [22].

\subsection{Sedentary behavior}

Sedentary behavior was assessed using a structured questionnaire with items about the amount of time habitually spent in front of the television (TV), computer (PC), or playing video games (VG) during school days and on school-free days. This included questions such as: "On weekdays, how many hours do you usually spend watching television?”, "On weekdays, how many hours do you usually spend on the computer?", and "On weekdays, how many hours do you usually spend playing video games?" The answers were classified into two categories: $<2 \mathrm{~h} / \mathrm{day}^{-1}$ and $\geq 2 \mathrm{~h} / \mathrm{day}^{-1}$. The 10 -min questionnaire was administered in the classroom, under the supervision of an HELENA fieldworker, during the morning before the PA assessment. This measure has been shown to have a reliable intraclass correlation $(0.82 ; 95 \% \mathrm{CI} 0.75-0.87)$ and criterion validity $(0.3)$ [23].

\subsection{Potential confounders}

Based on previous studies, we considered the following potential confounders study.

- City.

- BMI converted to z-scores [24].

- Parental educational level (PEL) (father and mother separately) collected with a specific questionnaire adapted from the 
International Standard Classification of Education (ISCED) (http://www.uis.unesco.org/Library/Documents/isced97-en. pdf) and scored as described previously [25].

- Smoking status, defined as the regular consumption of at least one cigarette per day in the past month [26].

\subsection{Statistics}

Data are presented as percentages for qualitative variables, and as the mean \pm standard deviation for quantitative variables. The normality of distribution was checked graphically and by using the Shapiro-Wilk test. To assess any potential bias linked to missing or incomplete data on PA or Tanner staging, the main characteristics of included and excluded participants were compared using Student's $t$-test for quantitative variables, a Chi-squared test for categorical variables and the Cochran-Armitage trend test for ordered categorical variables. To evaluate the magnitude of differences between included and excluded participants, we calculated the absolute standardized differences: a standardized difference $>20 \%$ denotes meaningful imbalance. All comparisons on the influence of pubertal status on PA change were conducted separately for boys and girls separately. We first compared the main participants' characteristics and recorded PA time between the two pubertal status categories; Student's t-test was used for quantitative variables, the chi-squared test for categorical variables and the Cochran-Armitage trend test for ordered categorical variables.

Next, we investigated the associations between pubertal status and PA (total counts) and during different periods (school-free days, school days, before and after school, during lessons and during recesses) after adjustment on prespecified confounding factors (namely the Z-score for BMI, PEL, smoking status and study center). We used linear mixed models including the city as random effects and other variables as fixed effects; adjusted means of physical activity ( \pm standard error of the mean, SEM) were calculated using the least-squares mean approach. Heterogeneities in associations of pubertal status with PA measures across gender were tested using formal interaction tests.

All statistical tests were performed with a two-tailed $\alpha$ level of 0.05 except for heterogeneity in which an $\alpha$ level of 0.10 was chosen. Data were analyzed using SAS software version 9.4 (SAS Institute Inc., Cary, NC, USA).

\section{Results}

\subsection{Study population}

Table 1 shows a comparison of the main characteristics of included participants 'i.e., with PA and Tanner staging data available) vs those excluded from statistical analyses. Except for age and the paternal educational level, we found no meaningful difference between the included and excluded participants. Table 2 shows the included participants' main characteristics and their accelerometer wearing time according to pubertal status for boys and girls separately. Boys and girls at post-pubertal stages were older, heavier, taller, and more often smokers compared with those at pre/midpubertal stages, and spent more time at school for lessons. The BMI $z$-scores did not differ between groups or genders.

\subsection{Total physical activity data}

After adjustment for the study city, BMI $z$-score, PEL, and smoking status, there was no significant difference in total PA during the whole one-week study between the pre/mid-pubertal and post-pubertal boys or girls (Fig. 1). However, post-pubertal boys accumulated fewer kcounts compared with their pre/mid pubertal peers (143 kcounts; $\mathrm{P}=0.07$ ). Based on time schedule during school days, post-puberty was associated with a significant difference (17.6\%) in total PA during school-free days only for boys (adjusted mean total counts: 679 kcounts in pre/mid-puberty vs 564 kcounts in post-puberty; $P=0.0007$; Fig. 1 ). Similarly, postpuberty was associated with a difference of $20 \%$ in total PA during recesses for boys (adjusted mean total counts: 162 kcounts in pre/mid-puberty vs 135 kcounts in post-puberty; $P=0.006$ ). A significant difference was observed in sedentary behavior. The percentage of boys who played VG $\geq 2 \mathrm{~h}$ /day was $33 \%$ higher in the postpubertal group than in the prepubertal group $(P=0.02)$ during school-free days, whereas there was no difference for TV and PC.

There was no difference between prepubertal vs postpubertal girls for PA in whole week, school free days and any period of school day.

\subsection{Moderate to vigourous physical activity data}

The difference of MVPA duration between prepubertal vs postpubertal boys was $14.6 \%$ (61.0 min vs $52.1 \mathrm{~min}$, respectively; $P=0.005$ ) for school-free days and $14.9 \%$ (7.4 min vs $6.3 \mathrm{~min}$, respectively; $P=0.038$ ) for school recesses in boys (see Fig. 2). There was no difference between prepubertal vs postpubertal group girls for MVPA in whole week, school free days and any period of school day.

\section{Discussion}

To our knowledge, this study is the first to investigate the impact of gender on PA during the transition to adolescence using a detailed weekly schedule and pubertal status (maturational status) as a marker of adolescent phase. The use of pubertal status (maturational status) instead of adolescence (chronological age) is a better approximation of the changes observed during adolescence. Most previous studies on the impact of this transitional period on PA have used age rather than pubertal status, and questionnaires instead of accelerometry for assessing PA, and did not take the time schedule during school days into consideration [8].

The PA level observed in the HELENA study was higher in boys than in girls, as has been previously observed in developing countries $[4,8,27,28]$. PA difference between prepubertal $v s$ postpubertal during whole week did not reach significance, probably due to the high variability in PA patterns observed. While there was no significant difference of PA between prepubertal $v s$ postpubertal during the whole week, the difference was significant during school-free days and recesses in boys. This result is consistent with the difference in PA observed in boys during non-organized times shown by Dale et al. [29]. A longitudinal by Sallis JF et al., reported an annual decline in PA of $2.7 \%$ for boys and $7.4 \%$ for girls throughout adolescence [30]. However, these studies did not analyze PA during school days and school-free days separately. Corder et al. showed changes in PA based on gender, age, and school-free days/school days [31]. The absence of PA differences between pubertal stages in girls was probably due to the lack of sedentary pursuits in girls suggested by Matthews et al. [28].

Concerning MVPA, between the pubertal stages studied, boys showed a significant difference during school free-days and recesses. MVPA duration between prepubertal vs postpubertal boys was $-17.6 \%$ for school free days and $-20 \%$ for recess.

Girls showed a trend of $+14.9 \%$ between prepubertal vs postpubertal girls (29.6 min vs 34.0 min, respectively; $P=0.09$ ) for MVPA during school free days. This suggest that there are changes in PA patterns among girls during puberty. These changes of PA 
Table 1

Main characteristics of included and non-included adolescents.

\begin{tabular}{|c|c|c|c|c|}
\hline & $\begin{array}{l}\text { Included } \\
\mathrm{N}=1842\end{array}$ & $\begin{array}{l}\text { Not included } \\
\mathrm{N}=1814\end{array}$ & P-value & $\begin{array}{l}\text { Absolute standardized } \\
\text { difference (\%) }\end{array}$ \\
\hline Gender (\%boys) & 49.7 & 45.5 & 0.012 & 8.5 \\
\hline Age $(y r)$ & $14.6 \pm 1.2$ & $14.9 \pm 1.3$ & $<0.0001$ & 21.3 \\
\hline Height $(\mathrm{cm})$ & $165.7 \pm 9.2$ & $165.9 \pm 9.1$ & 0.47 & 2.5 \\
\hline Body weight ( $k g$ ) & $58.4 \pm 12.3$ & $59.9 \pm 13.1$ & 0.0003 & 12.3 \\
\hline Z-score BMI & $0.3 \pm 0.9$ & $0.4 \pm 0.9$ & 0.86 & 8.8 \\
\hline Nutritional status (\%UW/\%NW/\%OW/\%O) ${ }^{\mathrm{a}}$ & $6.7 / 71.6 / 16.5 / 5.2$ & $5.4 / 69.9 / 18.7 / 6.0$ & 0.017 & 8.4 \\
\hline Father education level $(\% I / \% I I / \% I I I)^{\mathrm{b}}$ & $33.4 / 28.9 / 37.7$ & $42.9 / 26.5 / 30.6$ & $<0.0001$ & 20.2 \\
\hline Mother education level (\%I/\%II/\%III) $)^{\mathrm{b}}$ & $32.4 / 31.5 / 36.1$ & $37.8 / 31.2 / 31.0$ & 0.0003 & 12.7 \\
\hline Smoker (\%) & 15.5 & 20.1 & 0.0005 & 12.0 \\
\hline
\end{tabular}

a Nutritional status: underweight (UW), normal weight (NW), overweight (OW), obese (O), BMI: body mass index.

b PEL (Parental Education Level): lower education (I); higher secondary education (II); higher education or university degree (III).

Table 2

Characteristics of the subjects and accelerometer wearing time duration according to pubertal status stratified by gender.

\begin{tabular}{|c|c|c|c|c|c|c|}
\hline & \multicolumn{3}{|l|}{ Girls } & \multicolumn{3}{|l|}{ Boys } \\
\hline & $\begin{array}{l}\text { Pre/mid puberty } \\
\mathrm{N}=224\end{array}$ & $\begin{array}{l}\text { Post-puberty } \\
\mathrm{N}=702\end{array}$ & P-value & $\begin{array}{l}\text { Pre/mid puberty } \\
\mathrm{N}=301\end{array}$ & $\begin{array}{l}\text { Post puberty } \\
\mathrm{N}=615\end{array}$ & P-value \\
\hline \multicolumn{7}{|l|}{ Characteristics } \\
\hline Age $(y r)$ & $13.8 \pm 0.93$ & $14.8 \pm 1.1$ & $<0.0001$ & $13.8 \pm 0.9$ & $15.1 \pm 1.1$ & $<0.0001$ \\
\hline Height $(\mathrm{cm})$ & $159.6 \pm 7.1$ & $162.6 \pm 6.8$ & $<0.0001$ & $162.4 \pm 8.9$ & $173.1 \pm 7.6$ & $<0.0001$ \\
\hline Body weight ( $k g$ ) & $51.1 \pm 10.6$ & $57.0 \pm 9.4$ & $<0.0001$ & $54.5 \pm 14.4$ & $64.5 \pm 12.1$ & $<0.0001$ \\
\hline Z-score BMI & $0.1 \pm 1.0$ & $0.4 \pm 0.8$ & $<0.0001$ & $0.3 \pm 1.1$ & $0.4 \pm 0.9$ & 0.08 \\
\hline Nutritional status (\%UW/\%NW/\%OW/\%O) ${ }^{\mathrm{a}}$ & $12.0 / 73.2 / 10.3 / 4.5$ & $5.7 / 72.9 / 18.0 / 3.4$ & 0.009 & $10.0 / 65.4 / 14.6 / 10.0$ & $4.2 / 72.5 / 18.1 / 5.2$ & 0.94 \\
\hline Father education level (\%I/\%II/\%III) ${ }^{\mathrm{b}}$ & $26.5 / 29.9 / 43.6$ & $36.9 / 28.7 / 34.4$ & 0.003 & $35.0 / 27.8 / 37.2$ & $31.2 / 29.2 / 39.6$ & 0.31 \\
\hline Mother education level (\%I/\%II/\%III) $)^{\mathrm{b}}$ & $23.9 / 35.3 / 40.8$ & $36.8 / 29.0 / 34.2$ & 0.003 & $33.8 / 29.5 / 36.7$ & $29.9 / 33.8 / 36.2$ & 0.56 \\
\hline Smoker $(\%)$ & 5.8 & 20.3 & $<0.0001$ & 7.5 & 17.4 & $<0.0001$ \\
\hline \multicolumn{7}{|l|}{ Accelerometer wearing time ( $\mathrm{min} /$ day) } \\
\hline Whole week & $1019.0 \pm 0.1$ & $1018.9 \pm 1.0$ & 0.26 & $1019.0 \pm 0.3$ & $1019.0 \pm 0.5$ & 0.96 \\
\hline School day & $1019.0 \pm 0.1$ & $1018.9 \pm 1.2$ & 0.27 & $1019.0 \pm 0.4$ & $1019.0 \pm 0.8$ & 0.97 \\
\hline Before and after school & $649.1 \pm 79.7$ & $611.6 \pm 78.1$ & $<0.0001$ & $646.0 \pm 68.1$ & $622.2 \pm 77.8$ & $<0.0001$ \\
\hline Lessons & $305.5 \pm 59.5$ & $342.2 \pm 58.5$ & $<0.0001$ & $307.2 \pm 51.4$ & $333.6 \pm 58.5$ & $<0.0001$ \\
\hline Recess & $65.4 \pm 27.5$ & $65.9 \pm 30.8$ & 0.83 & $66.0 \pm 26.7$ & $64.0 \pm 30.0$ & 0.31 \\
\hline Free-day & $1019 \pm 0.0$ & $1019 \pm 0.1$ & 0.32 & $1019.0 \pm 0.1$ & $1019.0 \pm 0.3$ & 0.58 \\
\hline
\end{tabular}

a Nutritional status: underweight (UW), normal weight (NW), overweight (OW), obese (O).

b PEL: lower education (I); higher secondary education (II); higher education or university degree (III).

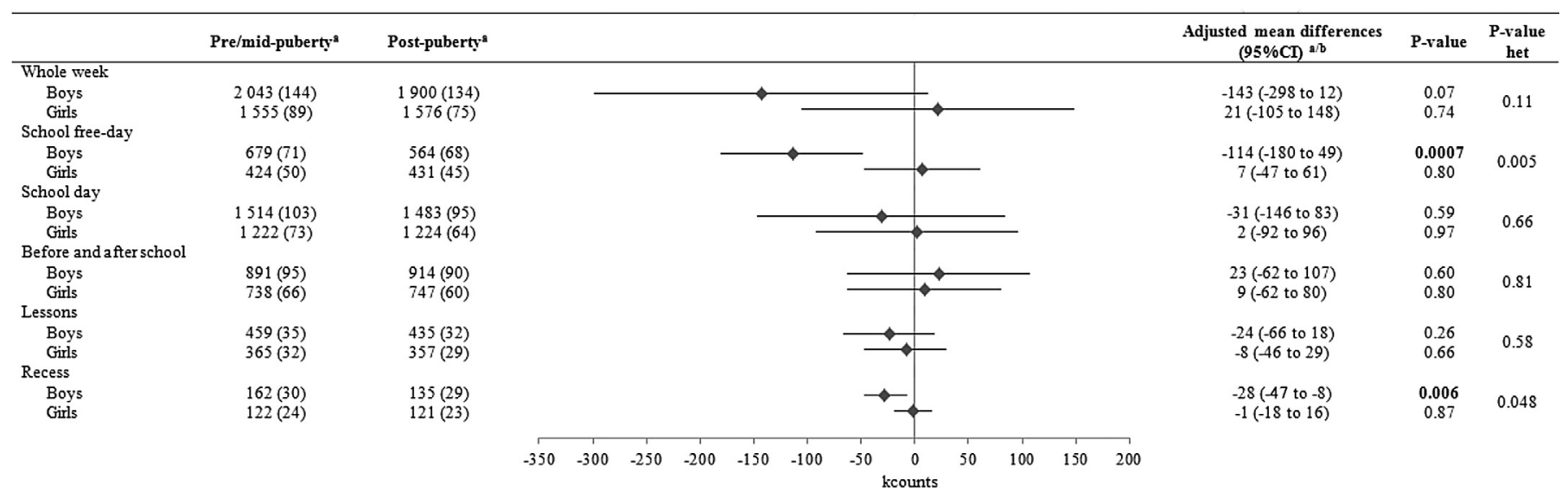

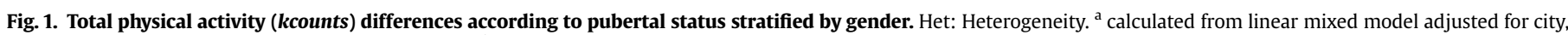
Z-score BMI, parental educational level and smoking. ${ }^{\mathrm{b}}$ calculated using pre/mid-puberty as reference group.

patterns were not statistically different probably due to the high variability in PA patterns observed.

This study showed a difference in PA between prepubertal vs postpubertal group, but only in boys during non-organized times such as recesses and school-free days. This difference in PA was not reversed during school periods, as was shown by Dale et al. [29]. This is probably because PA during school days is more organized.
In this context, PA during school days is less likely to change. Thus, this study confirms the crucial role of recesses for PA during school periods, as they provide good opportunities for PA promotion in all adolescents [32].

Some limitations of this study should be acknowledged. The main limitation was the cross-sectional design of the study which prevented us from describing within-individual PA change 


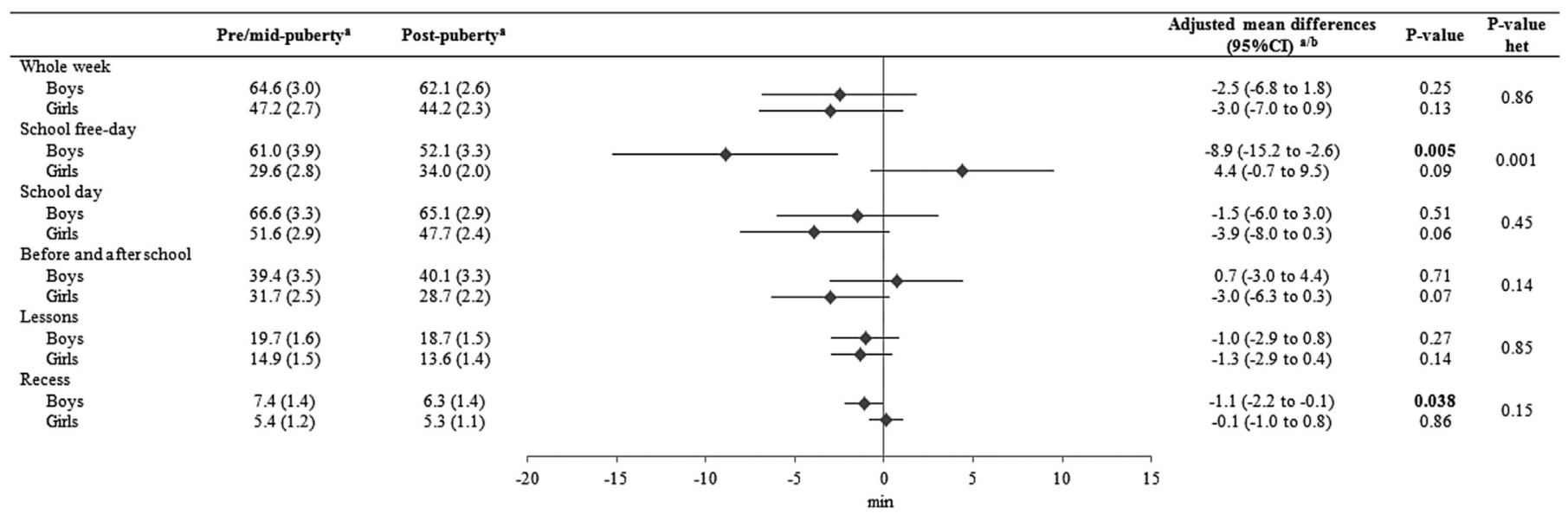

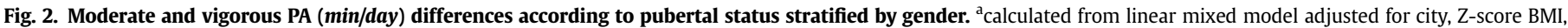
parental educational level and smoking. ${ }^{\mathrm{b}}$ calculated using pre/mid-puberty as reference group.

patterns. Another limitation was the difference in participants' ages and paternal education levels between those adolescents who were included $v s$ those excluded. The study strengths include the large sample sizes in seven European cities, the use of standardized procedures, inclusion of several confounding factors within the analyses, objective assessment of PA with prolonged wearing time, and the inclusion of school day schedule analysis.

Understanding the decline in PA during the transition to adolescence is useful for planning PA interventions. This study shown difference in PA between prepubertal vs postpubertal boys, especially less PA in postpubertal boys during non-organized time. This suggests that prepubertal boys become less active when they become postpubertal, especially during school-free days. The finding highlights the importance of emphasizing sports programs and hobbies that include PA for this population.

\section{Financial support}

The HELENA study was made possible by the financial support of the European Community Sixth RTD Framework Program (Contract FOOD-CT-20056007034) and the Spanish Ministry of Science and Innovation (RYC-2010-05957 and RYC-2011-09011).

\section{Author contributions}

The authors' contributions are as follows: L. A. M. coordinated the HELENA project at the international level; L. A. M., K. W., S. D., and F. G. were involved in the design of the HELENA project and locally coordinated the HELENA project; L. B. and J. $\mathrm{V}$. organized the fieldwork and collected the data locally; L. B. was responsible for regulatory issues; E. D. carried out the statistical analysis; L. B. drafted the article. J. H. M. was involved in the interpretation of data and revising article by providing significant advice and consultation. All authors read and approved the final manuscript.

\section{Conflict of interest}

Frederic Gottrand has received consulting fees from Numico Clinical Nutrition, lecture fees from SMS and grant support from Danone Research. The remaining authors state no conflict of interest. The content of this paper reflects only the authors' views, and the European Community is not liable for any use that may be made of the information contained therein.

\section{Acknowledgements}

The authors thank the participants for taking part in the study. The authors would like to thank the digest science foundation for its support. We thank also Anne GAUTREAU and Muriel BEUVRY (CIC-1403-CHU-Inserm de Lille, France) for help in typing this manuscript.

\section{Appendix A. Supplementary data}

Supplementary data to this article can be found online at https://doi.org/10.1016/j.clnu.2018.12.027.

\section{References}

[1] Ekelund U, Anderssen SA, K Froberg K, Sardinha LB, Andersen LB, Brage S. Independent associations of physical activity and cardiorespiratory fitness with metabolic risk factors in children: the European youth heart study. Diabetologia 2007;50:1832-40.

[2] Janssen I, Leblanc AG. Systematic review of the health benefits of physical activity and fitness in school-aged children and youth. Int J Behav Nutr Phys Activ 2010;7:40-5.

[3] Kwon S, Janz KF, Letuchy EM, Burns TL, Levy SM. Active Lifestyle in childhood and adolescence prevents obesity development in young adulthood. Obesity 2015;23:2462-9.

[4] Sallis JF, Prochaska JJ, Taylor WC. A review of correlates of physical activity of children and adolescents. Med Sci Sports Exerc 2000;32:963-75.

[5] Martinez-Gomez D, Ortega FB, Ruiz JR, Vicente-Rodriguez G, Veiga OL, Widhalm K, et al. Excessive sedentary time and low cardiorespiratory fitness in European adolescents: the HELENA study. Arch Dis Child 2011;96:240-6.

[6] Trost SG, Blair SN, Khan KM. Physical inactivity remains the greatest public health problem of the 21st century: evidence, improved methods and solutions using the '7 investments that work' as a framework. Br J Sports Med 2014:48:169-70.

[7] Ekelund U, Luan J, Sherar LB, Esliger DW, Griew P, Cooper A. Moderate to vigorous physical activity and sedentary time and cardiometabolic risk factors in children and adolescents. JAMA 2012:307:704-12.

[8] Dumith SC, Gigante DP, Domingues MR, Kohl HW. Physical activity change during adolescence: a systematic review and a pooled analysis. Int J Epidemiol 2011;40:685-98.

[9] Baquet G, Ridgers ND, Blaes A, Aucouturier J, Van PE, Berthoin S. Objectively assessed recess physical activity in girls and boys from high and low socioeconomic backgrounds. BMC Publ Health 2014;14:192-6.

[10] Beets MW, Vogel R, Forlaw L, Pitetti KH, Cardinal BJ. Social support and youth physical activity: the role of provider and type. Am J Health Behav 2006;30: 278-89.

[11] Salvy SJ, Bowker JW, Roemmich JN, Romero N, Kieffer E, Paluch R, et al. Peer influence on children's physical activity: an experience sampling study. J Pediatr Psychol 2008;33:39-49.

[12] Gracia-Marco L, Ortega FB, Ruiz JR, Williams CA, Hagstromer M, Manios Y, et al. Seasonal variation in physical activity and sedentary time in different European regions. The HELENA study. J Sports Sci 2013;31:1831-40.

[13] Beghin L, Huybrechts I, Vicente-Rodriguez G, De Henauwn S, Gottrand F, Gonzalez-Gross M, et al. Main characteristics and participation rate of 
European adolescents included in the HELENA study. Arch Publ Health 2012;70:1-11.

[14] Moreno LA, De Henauwn S, Gonzalez-Gross M, Kersting M, Molnar D, Gottrand F, et al. Design and implementation of the healthy Lifestyle in Europe by nutrition in adolescence cross-sectional study. Int J Obes (Lond) 2008;32:S4-11.

[15] Beghin L, Castera M, Manios Y, Gilbert CC, Kersting M, De Henauwn S, et al. Quality assurance of ethical issues and regulatory aspects relating to good clinical practices in the HELENA Cross-Sectional Study. Int J Obes (Lond) 2008;32:S12-8.

[16] Cole TJ, Lobstein T. Extended international (IOTF) body mass index cut-offs for thinness, overweight and obesity. Pediatr Obes 2012;7:284-94.

[17] Tanner JM. Normal growth and techniques of growth assessment. Clin Endocrinol Metabol 1986;15:411-51.

[18] Crowley SJ, Cain SW, Burns AC, Acebo C, Carskadon MA. Increased sensitivity of the circadian system to light in early/mid-puberty. J Clin Endocrinol Metabol 2015;100:4067-73.

[19] Martin CA, Kelly TH, Rayens MK, Brogli BR, Brenzel A, Smith WJ, et al. Sensation seeking, puberty, and nicotine, alcohol, and marijuana use in adolescence. J Am Acad Child Adolesc Psychiatr 2002;41:1495-502.

[20] Ruiz JR, Ortega FB, Martinez-Gomez D, Labayen I, Moreno LA, De Bourdeaudhuij I, et al. Objectively measured physical activity and sedentary time in European adolescents: the HELENA study. Am J Epidemiol 2011;174:173-84.

[21] Riddoch CJ, Bo AL, Wedderkopp N, Harro M, Klasson-Heggebo L, Sardinha LB, et al. Physical activity levels and patterns of 9- and 15-yr-old European children. Med Sci Sports Exerc 2004;36:86-92.

[22] Vanhelst J, Beghin L, Duhamel A, De Henauw S, Molnar D, Vicente Rodriguez G, et al. Relationship between school rhythm and physical activity in adolescents : the HELENA study. J Sports Sci 2017;35:1666-73.
[23] Dunstan DW, Barr ELM, Healy GN, Salmon J, Shaw JE, Balkau B, et al. Television viewing time and mortality the Australian diabetes, obesity and Lifestyle study (AusDiab). Circulation 2010;121:384-91.

[24] Cole TJ. The LMS method for constructing normalized growth standards. Eur J Clin Nutr 1990;44:45-60.

[25] Beghin L, Dauchet L, De Vriendt T, Cuenca-Garcia M, Manios Y, Toti E, et al Influence of parental socio-economic status on diet quality of European adolescents: results from the HELENA study. Br J Nutr 2014;111:1303-12.

[26] Malcon MC, Menezes AMB, Chatkin M. Prevalence and risk factors for smoking among adolescents. Revista De Saude Publica 2003;37:1-7.

[27] de Moraes AC, Carvalho HB, Rey-Lopez JP, Gracia-Marco L, Beghin L, Kafatos A, et al. Independent and combined effects of physical activity and sedentary behavior on blood pressure in adolescents: gender differences in two crosssectional studies. PLoS One 2013;8, e62006.

[28] Matthews CE, Chen KY, Freedson PS, Buchowski MS, Beech BM, Pate RR, et al. Amount of time spent in sedentary behaviors in the United States, 2003-2004. Am J Epidemiol 2008;167:875-81.

[29] Dale D, Corbin CB, Dale KS. Restricting opportunities to be active during schoo time: do children compensate by increasing physical activity levels after school? Res Q Exerc Sport 2000;71:240-8.

[30] Sallis JF. Epidemiology of physical activity and fitness in children and adolescents. Crit Rev Food Sci Nutr 1993;33:403-8.

[31] Corder K, Sharp SJ, Atkin AJ, Griffin SJ, Jones AP, Ekelund U, et al. Change in objectively measured physical activity during the transition to adolescence. Br J Sports Med 2015;49:730-6.

[32] Haapala HL, Hirvensalo MH, Laine K, Laakso L, Hakonen H, Lintunen T, et al Adolescents' physical activity at recess and actions to promote a physically active school day in four Finnish schools. Health Educ Res 2014;29:840-52. 